Gut, 1976, 17, 477-482

\title{
Proctocolitis and Crohn's disease of the colon: a comparison of the clinical course
}

\author{
J. E. LENNARD-JONES, JEAN K. RITCHIE, AND W. J. ZOHRAB
}

From St Mark's Hospital, London

SUMMARY This study suggests that proctocolitis is an illness with an acute and potentially dangerous onset but which appears to become less severe after survival for one year, whereas Crohn's colitis tends to be a more chronic and progressive illness over several years with a greater need for surgical treatment and a greater tendency to anal complications.

Proctocolitis and Crohn's disease of the colon were originally distinguished from one another by examination of colectomy specimens (Wells, 1952; Brooke, 1959; Lockhart-Mummery and Morson, 1960, 1964; Cornes and Stecher, 1961). Once the diagnosis had been established in this way, retrospective analysis of the case records enabled the clinical features of the two disorders to be recognised. In two series of patients treated surgically for colitis the pathological feaures in the excised colon have been correlated with the clinical course of the illness (Farmer et al., 1968; Glotzer et al., 1970). The anatomical distinctions between the two types of colitis have been further clarified by a critical analysis of the findings in colectomy specimens removed from patients with a clear diagnosis of either ulcerative colitis or Crohn's colitis (Cook and Dixon, 1973).

Any series in which the distinction between the two types of colitis is based upon examination of the excised colon must be limited to the more severe types of illness. To avoid this bias towards severe disease in the present comparison of the clinical course of proctocolitis and Crohn's colitis, the diagnosis was made in many patients without operation. The additional selective factor introduced by more that one admission to hospital was avoided by limiting the study to patients admitted to hospital for the first time for treatment of colitis.

Clinical diagnosis in this paper is based on anatomical criteria found on examination of the anal canal, endoscopic examination of the rectum and colon, radiology of the small and large intestine, and biopsy. The scoring system proposed by LennardJones (1971) is used for the diagnosis of Crohn's disease. Proctocolitis is defined by the small number

Received for publication 18 March 1976 of criteria shown to have the greatest discriminating value by cluster and pattern analysis (Jones et al., 1973; Spicer et al., 1973). The distinctions between proctocolitis and Crohn's colitis in this study accord closely with the descriptions and definitions of Schachter and Kirsner (1975).

\section{Methods}

\section{SELECTION OF PATIENTS}

The records of all patients admitted to St. Mark's Hospital with non-specific colitis during the decade 1963-72 were reviewed. The patients admitted to hospital for the first time on account of colitis during this period were selected for study. Previous admission to this, or another, hospital for the treatment of an anal lesion did not preclude the patient from study provided that there had been no evidence of, or treatment for, colitis at that time.

Patients with both Crohn's ileocolitis and colitis (Schachter and Kirsner, 1975) were included in this study but, as its purpose was to contrast two forms of colitis, patients with ileal involvement were included only if this was slight in comparison with the colonic disease and not causing obstruction. All patients with ileal involvement also had disease affecting at least half the colon; patients with colorectal disease alone were included irrespective of the distribution of the disease within the large bowl.

DiAgNOSTIC CRITERIA

Proctocolitis was defined as the presence of continuous mucosal disease involving the rectum and extending in continuity for a variable distance proximal to the rectum, associated with granularity of the mucosal line on double-contrast barium enema, mucin depletion or mucosal atrophy on biopsy, but without granulomata. Crohn's colitis 
was defined either as the presence of epithelioid cell granulomata and one of the features listed below (34 patients initially and eight later) or the absence of granulomata and any three of the following features (16 patients): (1) discontinuous disease shown by sigmoidoscopy, rectal biopsy, radiographs, or an operative specimen; (2) characteristic terminal ileal disease on radiographs or in an operation specimen (seven patients); (3) deep fissures shown by radiographs or in an operation specimen; (4) enterocutaneous fistula; (5) chronic anal lesion; (6) normal mucin content of epithelial cells in the presence of mucosal inflammation on biopsy; (7) the presence of lymphoid aggregates in the mucosa and submucosa.

With these criteria, 130 patients with proctocolitis and 58 patients with Crohn's disease, all admitted to hospital for the first time, were included in the study. Twelve patients could not be allocated to either group and were, therefore, excluded.

Follow-up was continued until 1 June 1974 and life tables were constructed to show the mortality and likelihood of surgical treatment in the two groups of patients. Comparison with expected mortality was calculated from the English Life Tables no. 12 (Registrar General, 1961) and using the programme MYCL (Hill, 1972).

\section{Results}

\section{CLINICAL FEATURES ON ADMISSION}

The two groups of patients are compared in Table 1. The sex ratio was reversed in the two conditions; almost three-fifths of the patients with proctocolitis were male and a similar proportion of patients with Crohn's colitis were female. The reason for admission to hospital differed markedly in the two groups: $68 \%$ of the patients with proctocolitis were admitted with acute symptoms (defined as an increased bowel frequency of less than three months' duration, accompanied by weight loss and fever) compared with $41 \%$ of the patients with Crohn's colitis. Conversely, proportionally more of the patients with Crohn's disease were admitted for chronic illness.

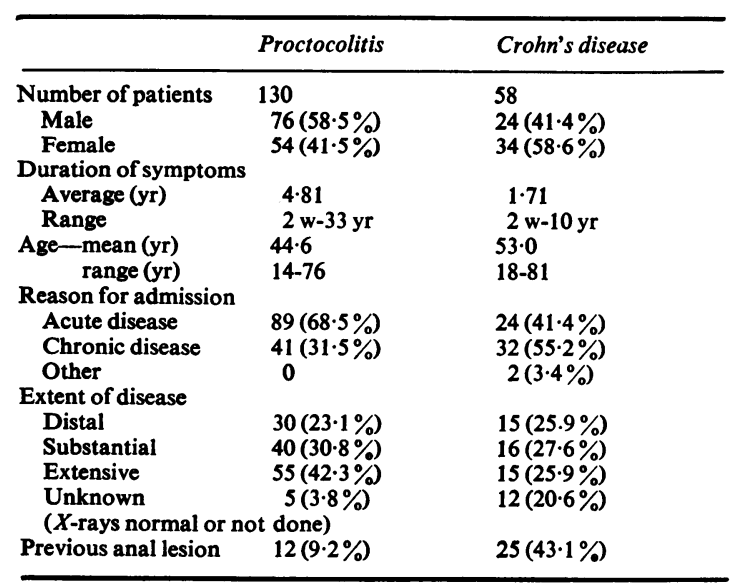

Table 1 Comparison of the two groups of patients

Considerably more of the patients with Crohn's disease gave a history of a previous anal lesion- $-43 \%$ compared with $9 \%$ of the patients with proctocolitis.

The extent of the disease during the first admission was estimated radiologically. It was defined as 'distal' if it involved the rectum and/or the sigmoid colon; 'extensive' if it involved the whole colon from the rectum up to and including the hepatic flexure, or 'substantial' if it was intermediate in extent. Comparison is difficult as, in 10 of the patients with Crohn's disease, the radiographs showed no mucosal abnormality; this reflects the fact that mucosal abnormalities are more difficult to demonstrate radiologically in Crohn's colitis than in proctocolitis. In general, however, the proportion of patients having distal or substantial involvement was similar in the two groups, while the proportion with extensive disease tended to be higher in the proctocolitis group. Older patients with Crohn's colitis tended to have distal or substantial disease while younger patients usually had extensive involvement; no such trend was demonstrable in proctocolitis (Table 2). Similar findings are obtained if the age of onset of symptoms is analysed rather than the age at the first hospital admission.

\begin{tabular}{|c|c|c|c|c|c|c|c|c|c|}
\hline & & \multicolumn{8}{|c|}{ Age group (yr) } \\
\hline & & $10-19$ & $20-29$ & $30-39$ & $40-49$ & $50-59$ & $60-69$ & $70-79$ & $80-89$ \\
\hline Proctocolitis & $\begin{array}{l}\text { Distal } \\
\text { Substamtial } \\
\text { Extensive }\end{array}$ & $\begin{array}{l}1 \\
3 \\
4\end{array}$ & $\begin{array}{l}9 \\
8 \\
8\end{array}$ & $\begin{array}{l}4 \\
5 \\
9\end{array}$ & $\begin{array}{r}4 \\
4 \\
15\end{array}$ & $\begin{array}{l}4 \\
7 \\
9\end{array}$ & $\begin{array}{l}6 \\
9 \\
7\end{array}$ & $\begin{array}{l}2 \\
4 \\
3\end{array}$ & $\begin{array}{l}\mathbf{0} \\
\mathbf{0} \\
\mathbf{0}\end{array}$ \\
\hline & $\begin{array}{l}\text { Distal } \\
\text { Substantial } \\
\text { Extensive }\end{array}$ & $\begin{array}{l}0 \\
0 \\
1\end{array}$ & $\begin{array}{l}0 \\
1 \\
7\end{array}$ & $\begin{array}{l}0 \\
2 \\
1\end{array}$ & $\begin{array}{l}0 \\
1 \\
4\end{array}$ & $\begin{array}{l}6 \\
1 \\
2\end{array}$ & $\begin{array}{l}6 \\
5 \\
0\end{array}$ & $\begin{array}{l}2 \\
5 \\
0\end{array}$ & $\begin{array}{l}1 \\
1 \\
0\end{array}$ \\
\hline
\end{tabular}

Table 2 Extent of disease and age distribution in two groups of patients showing differing age distribution among patients with distal and extensive Crohn's colitis 
OUTCOME OF FIRST HOSPITAL ADMISSION

The outcome of the first admission is shown in Table 3. The proportion of patients requiring surgical treatment was similar in the two groups. Three patients with proctocolitis died, two during medical treatment and one after urgent surgical treatment for acute disease that did not respond to medical measures. Such urgent operations were required more frequently in patients with proctocolitis than in patients with Crohn's disease $(\mathrm{P}<0.025)$. Patients with Crohn's disease required more anal operations and in two patients an intraperitoneal abscess was drained.

\begin{tabular}{lll}
\hline & Proctocolitis & Crohn's disease \\
\hline Number of patients & 130 & 58 \\
Medical treatment & $94(72 \cdot 3 \%)(2$ died) & $46(79 \cdot 3 \%)$ \\
Anal operations & 2 & 6 \\
Drainage abscess & 0 & 2 \\
Surgical treatment & $36(27 \cdot 7 \%)$ & $12(20 \cdot 7 \%)$ \\
Elective operation & 11 & 9 \\
Urgent operation & $25(1$ died) & 3 \\
Deaths & $3(2 \cdot 3 \%)$ & 0 \\
\hline
\end{tabular}

Table 3 Outcome of first admission

\section{Mortality}

The overall mortality in the two groups of patients has been compared and the only significant difference
(P $<0.01$ ) is during the first year from the date of admission in which seven patients with proctocolitis died and all the patients with Crohn's colitis survived. Thereafter the mortality rates were similar and the probability of surviving eight years was $81 \%$ in patients with proctocolitis and $73 \%$ in patients with Crohn's disease. The causes of death and the time after the first admission in the two groups of patients are set out in Table 4. In the colitic patients, five of the deaths must be considered to be related to the disease-that is, two deaths after urgent surgical treatment, the death from hypoproteinaemia complicating acute colitis, and the two deaths from acute pancreatitis and staphylococcal pneumonia respectively which occurred while the patients were in hospital under treatment for acute colitis. No patient with Crohn's disease died either from the disease or its complications.

The mortality in these patients is compared with the expected mortality in a sample of the general population with the same age and sex distribution in Table 5. Fifteen of the patients with proctocolitis died compared with the expected mortality of $10 \cdot 12$ -that is, an excess mortality of almost $50 \%$. The number of expected deaths in the patients with Crohn's colitis was 9.45 and the actual deaths 8that is, rather lower than the number expected.

\begin{tabular}{|c|c|c|c|c|}
\hline & $\operatorname{Sex}$ & Cause & $\begin{array}{l}\text { Age } \\
(y r)\end{array}$ & $\begin{array}{l}\text { Year after first } \\
\text { admission }\end{array}$ \\
\hline \multicolumn{5}{|l|}{ Proctocolitis } \\
\hline \multirow[t]{5}{*}{ Related deaths } & $\mathbf{M}$ & Peritonitis after urgent operation & 63 & $<1$ \\
\hline & $\mathbf{M}^{*}$ & Acute pancreatitis & 76 & $<1$ \\
\hline & $\mathbf{M}^{*}$ & Staphylococcal pneumonia & 74 & $<1$ \\
\hline & $\mathbf{F}$ & Hypoproteinaemia complicating acute colitis & 40 & $<1$ \\
\hline & $\mathbf{F}$ & Subphrenic abscess after urgent operation & 66 & $2+$ \\
\hline \multicolumn{5}{|l|}{ Unrelated deaths } \\
\hline & $\mathbf{M}$ & Coronary thrombosis & 57 & $<1$ \\
\hline & $\mathbf{F}$ & Coronary thrombosis & 73 & $<1$ \\
\hline & $\mathbf{M}$ & Acute left ventricular failure & 75 & $<1$ \\
\hline & $\mathbf{F} \ddagger$ & Carcinomatosis: unknown primary & 40 & $2+$ \\
\hline & $\mathbf{M}$ & Essential hypertension & 69 & $2+$ \\
\hline & $\mathbf{F} \dagger$ & Metastases from carcinoma of colon & 49 & $3+$ \\
\hline & $\mathbf{F}$ & Coronary thrombosis & 74 & $5+$ \\
\hline & $\mathbf{F}$ & Left ventricular failure & 79 & $5+$ \\
\hline & $\mathbf{M}$ & Suicide & 64 & $6+$ \\
\hline & $\mathbf{M}$ & Cerebrovascular accident & 69 & $7+$ \\
\hline \multicolumn{5}{|l|}{$\begin{array}{l}\text { Crohn's disease } \\
\text { Unrelated deaths }\end{array}$} \\
\hline & $\mathbf{M}$ & Accidental death & 81 & $1+$ \\
\hline & $\mathbf{M}$ & Carcinoma of oesophagus & 70 & $1+$ \\
\hline & $\mathbf{F}$ & Cerebral embolus & 63 & $1+$ \\
\hline & $\mathbf{M}$ & Influenzal pneumonia & 78 & $3+$ \\
\hline & $\mathbf{M}$ & Influenzal pneumonia & 67 & $3+$ \\
\hline & $\mathbf{F}$ & Coronary thrombosis & 69 & $6+$ \\
\hline & $\mathbf{F}$ & Chronic renal failure & 87 & $7+$ \\
\hline & $\mathbf{M}$ & Ischaemic heart disease & 70 & $7+$ \\
\hline
\end{tabular}

Table 4 Causes of death in two groups of patients

* While in hospital under medical treatment for colitis.

+ Carcinoma proximal to distal colitis and considered to be unassociated.

$\ddagger$ Two and a half years after total proctocolectomy; no evidence of colorectal carcinoma in specimen. 


\begin{tabular}{lcclll}
\hline & \multicolumn{2}{l}{ Proctocolitis } & & \multicolumn{2}{l}{ Crohn's disease } \\
\cline { 2 - 3 } \cline { 5 - 6 } & $\begin{array}{l}\text { Expected } \\
\text { deaths }\end{array}$ & $\begin{array}{l}\text { Actual } \\
\text { deaths }\end{array}$ & & $\begin{array}{l}\text { Expected } \\
\text { deaths }\end{array}$ & $\begin{array}{l}\text { Actual } \\
\text { deaths }\end{array}$ \\
\hline Male & $6 \cdot 28$ & 8 & & $4 \cdot 27$ & 5 \\
Female & 3.93 & 7 & & $5 \cdot 18$ & 3 \\
Total & $10 \cdot 21$ & 15 & & $9 \cdot 45$ & 8 \\
\hline
\end{tabular}

Table 5 Expected and observed mortality

\section{LIKELIHOOD OF SURGICAL TREATMENT}

The likelihood of operation in the two groups is illustrated in the Figure. During the first year the operation rates were high in both groups. After the first two years, the operation rate in patients with proctocolitis was low, but the rate among patients with Crohn's disease continued to increase until the sixth year. The differences for the sixth and subsequent years are unlikely to have occurred by chance ( $P<0.01$ ). The chance of requiring operation among patients with Crohn's colitis was $72 \%$ within six years of the first admission to hospital compared with $44 \%$ among patients with proctocolitis.

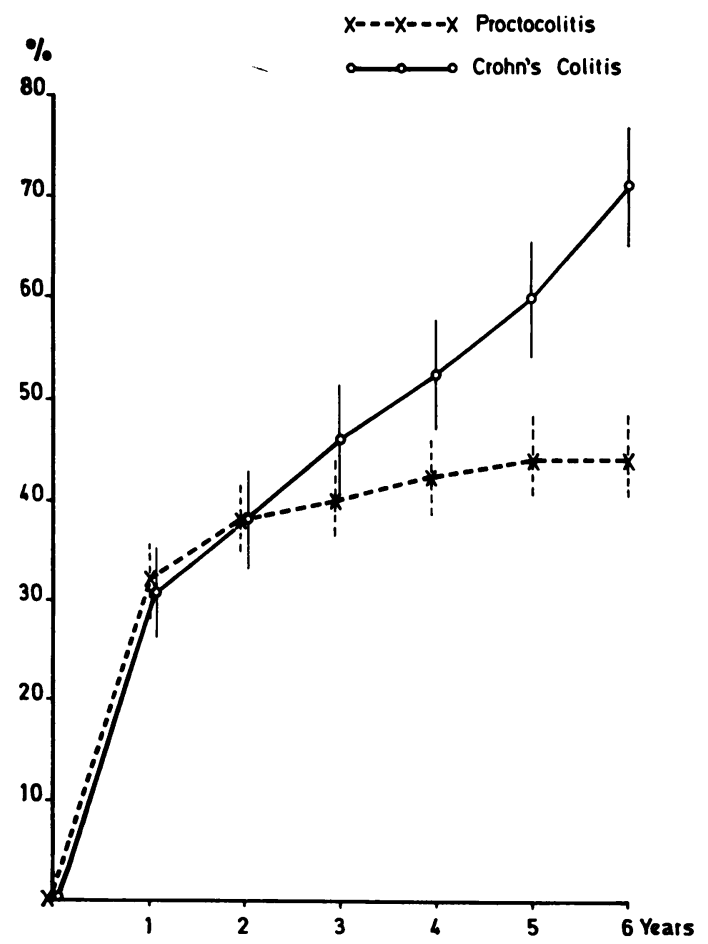

Figure Cumulative likelihood (\%) of requiring major surgical treatment during the six years after first admission to hospital among 130 patients with proctocolitis and 58 patients with Crohn's colitis. (Vertical bars indicate standard error).
Anal operations

During the follow-up period eight patients with Crohn's colitis and two patients with proctocolitis required local surgical treatment for an anal lesion.

\section{Discussion}

Studies of diagnostic criteria have shown that it is possible, in most cases, to differentiate proctocolitis from Crohn's colitis without the need for examination of a colectomy specimen (Jones et al., 1973; Spicer et al., 1973). Thus it has become possible to study groups of patients with these two disorders from the time of the first admission to hospital. Selection of patients by hospital admission clearly takes no account of the fact that patients with one or other form of colitis may require admission more frequently because of differing severity in the two types. Unfortunately, diagnostic studies tend to be less complete in outpatients and data for both outpatients and inpatients is not, at present, available for analysis.

At the time of admission to hospital the age of the patients and duration of the illness were not greatly different. However, the sex ratio was reversed, Crohn's colitis being commoner among women. More patients with Crohn's disease gave a past history of an anal lesion. The recent history gave evidence of more acute symptoms among patients with proctocolitis. The different anatomical distribution of Crohn's colitis in various age groups has been reported previously in a larger series from this hospital (Lockhart-Mummery, 1972). The tendency for Crohn's disease to involve the entire colon in younger patients and the distal colon in older patients is not so marked in the large series analysed by Farmer et al. (1975), though a similar trend is apparent in their figures.

During the first admission to hospital, the findings of this study show that the two diseases tend to follow a different course. Proctocolitis was found to be more acute, urgent surgical treatment was required more often, and there was a mortality. Crohn's colitis, on the other hand, more often required admission for chronic symptoms, elective operation was undertaken relatively more frequently, and there were no deaths. As expected, anal surgery was required during the first admission in more patients in the Crohn's $(10.4 \%)$ than in the proctocolitis group $(1.5 \%)$.

During the year from the first day of admission to hospital there was a significantly greater mortality among patients with proctocolitis than among patients with Crohn's colitis, none of whom died. Thereafter, the mortality was low in both groups. A similar finding in proctocolitis has been observed by 
Bonnevie et al. (1974). Among their series of 332 patients with proctocolitis followed from the time of first diagnosis, the mortality was significantly greater than expected only during the first year of observation.

A similar proportion of patients in both groups required colectomy during the first year after admission. In successive years, an interesting difference emerges. The proportion of patients with proctocolitis requiring operation rose more slowly than during the first year but the proportion requiring surgical treatment for Crohn's colitis rose steadily until the difference between the two groups became significant at the sixth year.

Three other comparisons between the clinical course of proctocolitis and Crohn's colitis have been based on diagnosis from colectomy specimens. An acute onset, as in this study, was found more frequently in proctocolitis $(29.5 \%)$ than Crohn's colitis $(11.1 \%)$ by Cornes and Stecher (1961); toxic dilatation of the colon was similarly noted to be more common in proctocolitis (Farmer et al., 1968). A tendency for patients with Crohn's colitis to need colectomy earlier in the course of the illness has been noted by Cornes and Stecher (1961) and by Glotzer et al. (1970). A poor long-term response to medical therapy has been described among children with granulomatous colitis by Korelitz et al. (1968).

It was not the purpose of the present study to compare the postoperative course of patients with the two types of colitis; follow-up data for patients treated surgically for proctocolitis (Baker, 1970; Ritchie, 1972) and for Crohn's colitis (Baker, 1971; Ritchie and Lockhart-Mummery, 1973) has already been reported from this hospital. These studies and those from other centres have shown that there is a risk of recurrent inflammation proximal to an ileostomy or anastomosis in Crohn's colitis.

From the present study of hospital inpatients and from other published reports, proctocolitis therefore emerges as an illness with an acute and potentially dangerous onset but which appears to become less severe after survival for one year. Crohn's colitis, in contrast, tends to be a more chronic and progressive illness over several years with a greater tendency to anal complications.

\section{Summary}

This study contrasts the clinical course of 130 patients with proctocolitis and 58 patients with Crohn's colitis from the time of their first admission to hospital during the years 1963-72.

Proportionally more of the patients with proctocolitis were admitted with acute symptoms. During the first admission, operation rates were similar but urgent surgery was required more frequently in the proctocolitic group. From the second to the sixth years, the operation rate was low in patients with proctocolitis but continued to increase in patients with Crohn's disease. Local surgery for anal lesions was more common in patients with Crohn's colitis.

Five of the patients with proctocolitis but none of the patients with Crohn's disease died from causes related to the disease; the observed mortality in the former group was almost $50 \%$ higher than that expected and the highest mortality was found in the first year of observation.

The results suggest that proctocolitis is more severe in its initial stages than Crohn's colitis but appears to decrease in severity after the first year of observation. Colonic Crohn's disease is a more chronic illness which, while not associated with an increased mortality in this series, requires more frequent surgical intervention in later years.

We are very grateful to Mr I. D. Hill of the Division of Medical Computing, Medical Research Council, for carrying out the MYCL analysis of the data. We wish to thank Mr D. J. Smale and his staff of the National Health Service Central Register for their assistance in tracing patients lost to hospital followup. Miss J. W. Phillips and the staff of the Records Department at St. Mark's Hospital gave invaluable help. W. J. Zohrab was the recipient of an Ontario Government Travelling Fellowship.

\section{References}

Baker, W N. W. (1970). The results of ileorectal anastomosis at St. Mark's Hospital from 1953 to 1968. Gut, 11, 235-239.

Baker, W. N. W. (1971). Ileorectal anastomosis for Crohn's disease of the colon. Gut, 12, 427-431.

Bonnevie, O., Binder, V., Anthonisen, P., and Riis, P. (1974). The prognosis of ulcerative colitis. Scandinavian Journal of Gastroenterology, 9, 81-91.

Brooke, B. N. (1959). Granulomatous diseases of the intestine. Lancet, 2, 745-749.

Cook, M. G., and Dixon, M. F. (1973). An analysis of the reliability of detection and diagnostic value of various pathological features in Crohn's disease and ulcerative colitis. Gut, 14, 255-262.

Cornes, J. S., and Stecher, M. (1961). Primary Crohn's disease of the colon and rectum. Gut, 2, 189-201.

Farmer, R. G., Hawk, W. A., and Turnbull, R. B. Jr (1968). Regional enteritis of the colon: a clinical and pathologic comparison with ulcerative colitis. American Journal of Digestive Diseases, 13, 501-514.

Farmer, R. G., Hawk, W. A., and Turnbull, R. B. (1975). Clinical patterns in Crohn's disease: a statistical study of 615 cases. Gastroenterology, 68, 627-635.

Glotzer, D. J., Gardner, R. C., Goldman, H., Hinrichs, H. R., Rosen, H., and Zetzel, L. (1970). Comparative features and course of ulcerative and granulomatous colitis. New England Journal of Medicine, 282, 582-587.

Hill, I. D. (1972). Computing man years at risk. British Journal of Preventive and Social Medicine, 26, 132-134.

Jones, J. H., Lennard-Jones, J. E., Morson, B. C., Chapman, 
M., Sackin, M. J., Sneath, P. H. A., Spicer, C. C., and Card, W. I. (1973). Numerical taxonomy and discriminant analysis applied to non-specific colitis. Quarterly Journal of Medicine, 42, 715-732.

Korelitz, B. I., Gribetz, D., and Kopel, F. B. (1968). Granulomatous colitis in children: a study of 25 cases and comparisons with ulcerative colitis. Pediatrics, 42, 446-457.

Lennard-Jones, J. E. (1971). Definition and diagnosis. In Regional Enteritis (Crohn's Disease). Skandia International Symposium, pp. 105-112. Edited by A. Engel and T. K. L. Larsson. Nordiska Bokhandelns: Stockholm.

Lockhart-Mummery, H. E. (1972). Crohn's disease of the large bowel. British Journal of Surgery, 59, 823-826.

Lockhart-Mummery, H. E., and Morson, B. C. (1960). Crohn's disease (regional enteritis) of the large intestine and its distinction from ulcerative colitis. Gut, 1, 87-105.

Lockhart-Mummery, H. E., and Morson, B. C. (1964). Crohn's disease of the large intestine. Gut, 5, 493-509.
Ritchie, J. K. (1972). Ulcerative colitis treated by ileostomy and excisional surgery. Fifteen years' experience at St. Mark's Hospital. British Journal of Surgery, 59, 345-351.

Ritchie, J. K., and Lockhart-Mummery, H. E. (1973). Nonrestorative surgery in the treatment of Crohn's disease of the large bowel. Gut, 14, 263-269.

Schachter, H., and Kirsner, J. B. (1975). Definitions of inflammatory bowel disease of unknown etiology. Gastroenterology, 68, 591-600.

Spicer, C. C., Jones, J. H., and Lennard-Jones, J. E. (1973). Discriminant and Bayes analysis in the differential diagnosis of Crohn's disease and proctocolitis. Methods of Information in Medicine, 12, 118-122.

Registrar General's Decennial Supplement: England and Wales 1961. HMSO: London.

Wells, C. (1952). Ulcerative colitis and Crohn's disease. Annals of the Royal College of Surgeons of England, 11, 105-120. 